\title{
Public awareness of and support for smoke-free legislation in Turkey: a national survey using the lot quality sampling technique
}

\author{
B. Cakir, T. Buzgan, ${ }^{2}$ S. Com, ${ }^{2}$ H. Irmak, ${ }^{2}$ E. Aydin ${ }^{2}$ and C. Arpad ${ }^{1}$
}

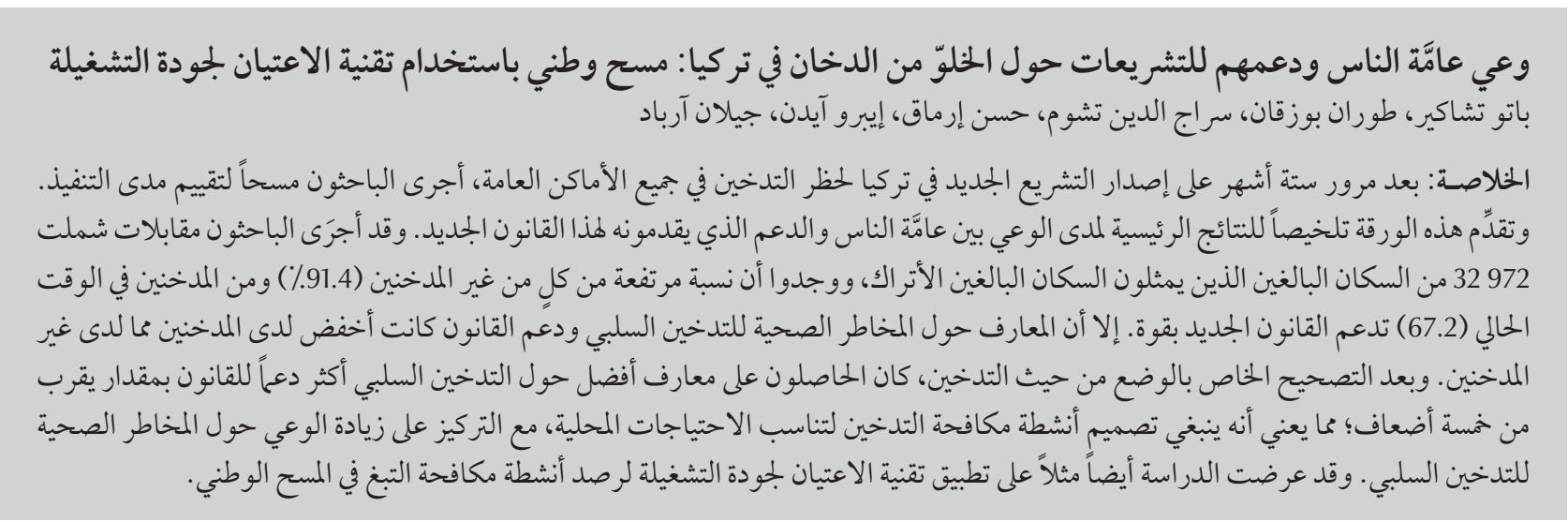

ABSTRACT Six months after new legislation in Turkey banning smoking in all public places, a national survey was carried out to assess its implementation. This paper summarizes the main findings on the public's awareness of and support for the new law. In a household interview survey of 32972 adults representative of the Turkish adult population, a high proportion of both non-smokers and current smokers (91.4\% and $67.2 \%$ respectively) strongly supported the new law. Knowledge about the health hazards of passive smoking and support for the law, however, were relatively lower among smokers than non-smokers. After controlling for smoking status, people with better knowledge about passive smoking were over 5 times more likely to support the new law. Tobacco control activities should be tailored to local needs, with a focus on increasing awareness about the health hazards of passive smoking. The study also demonstrated application of the lot quality sampling technique (LQT) for monitoring tobacco control activities in a national survey.

Sensibilisation et soutien du public à la législation antitabac en Turquie : enquête nationale recourant à l'échantillonnage par lots pour l'assurance qualité

RÉSUMÉ Six mois après la nouvelle législation en Turquie interdisant le tabac dans tous les lieux publics, une enquête nationale a été menée pour évaluer sa mise en œuvre. Le présent article résume les principaux résultats sur la sensibilisation du public à la nouvelle législation antitabac et son soutien en la matière. Dans une enquête par entretien auprès des ménages portant sur 32972 adultes représentatifs de la population adulte turque, une proportion élevée de non-fumeurs et de fumeurs (91,4\% et 67,2 \% respectivement) soutenait fortement la nouvelle législation. Les connaissances sur les risques sanitaires du tabagisme passif et le soutien à la loi étaient toutefois plus faibles chez les fumeurs que chez les non-fumeurs. Après vérification du statut tabagique, les adultes ayant davantage de connaissances sur le tabagisme passif étaient plus de cinq fois plus susceptibles de soutenir la nouvelle loi. II faut adapter les activités de lutte antitabac aux besoins locaux en faisant davantage de sensibilisation aux risques sanitaires du tabagisme passif. L'étude a aussi permis de mettre en application la technique d'échantillonnage par lots pour l'assurance qualité dans le cadre suivi du activités de lutte antitabac dans une enquête nationale.

'Department of Public Health, Faculty of Medicine, Hacettepe University, Ankara, Turkey (Correspondence to B. Cakir: bcakir@hacettepe.edu.tr). ${ }^{2}$ General Directorate of Primary Health Care Services, Ministry of Health, Ankara, Turkey.

Received: 24/10/10; accepted: 18/04/11 


\section{Introduction}

In January 2008 Turkey passed new legislation on tobacco control, to be implemented in 2 phases. The first phase prohibited smoking inside all public places and workplaces in Turkey and went into effect in May 2008. The second phase, in July 2009, was to further prevent smoking inside all public places, including inside all restaurants, bar and cafes and their open spaces. The 18-month period between the 2 phases was expected to help in the readjustment process of smokers, as an adaptation period. Even a complete tobacco ban, however, may not be effective in tobacco control unless it is well-known and supported by the public. Observations and general agreement over the 6 months after the enactment of the law seemed to indicate that there had been a dramatic decrease in smoking in public and workplaces. However, almost no scientific evidence was available about the impact of the new law [1] and, given that the second phase of the law would bring in more restrictions on smoking behaviour, it was felt essential to investigate the public's knowledge about the new law, their support for it, the effectiveness of earlier bans on tobacco advertising, promotion and sponsorship and the public's compliance with the tobacco control ordinances in general. The ultimate goal was to be fully prepared for potential obstacles in implementation of the second phase of the law.

A national survey was therefore carried out 6 months after the implementation of the first phase of the $100 \%$ smoke-free law in Turkey. Of several available sampling methodologies, the authors chose to use the lot quality sampling technique (LQT), which is an easy, quick, low-cost method developed by the World Health Organization (WHO) [2-4]. While traditional survey methods are preferable for providing information on prevalence rates at the regional and national levels, this method makes it possible to conduct surveys in small geographical or population-based areas ("lots") using small sample sizes in a cost-efficient way. To our knowledge, this is the first study using LQT in a tobacco-related survey. Details of the national survey and full set of analytical tables are presented elsewhere [5]. This paper summarizes the main findings on the public's awareness of and support for the new smoke-free legislation and demonstrates application of the LQT for monitoring tobacco control ordinances in a national survey.

\section{Methods}

\section{Study design and sampling strategy}

The target population in this national, cross-sectional survey was all Turkish adults (aged 15 years or over) residing in all 81 cities, corresponding to about 51 million individuals. The confidence level was set at $95 \%$ and the accuracy level at $\pm 5 \%$. The threshold levels to identify special subpopulations within each city with lower than acceptable rates were determined by the Ministry of Health $(\mathrm{MoH})$ as $<85 \%$ for the prevalence of awareness of the new smoke-free legislation and/ or passive smoking and $<70 \%$ for the prevalence of support for the new law. Correspondingly, 384 fully-completed surveys in each of the 81 provinces were determined as the minimum sample size required [6]. The minimum number of questionnaires to be completed in each province was rounded to 400 , corresponding to a minimum of 32400 interviews nationwide.

In each city, the lots were determined by the provincial health directorate as the official/administrative units through which they provided educational activities and/or interventions. Lots were chosen either as districts, community health centres, family medicine service areas and/or district health directorate service areas, as appropriate for the health care structure in the city. In addition, in each city, this sample size of 400 was divided by the number of lots determined for that city; for each lot, the required minimum number calculated was rounded to the upper integer. Decision values were calculated based on the topic of interest and the lot sample size in that particular city.

The most commonly used sampling frames were household registry records of the $\mathrm{MoH}$, which are updated annually by local health officials. In cities where family medicine practice was in use (about 25 cities), family medicine listings were used as the sampling frame. In small rural areas where no listing was available ( $<5 \%$ of the whole adult population), maps were used to identify areas for interviews. Given that individuals reached at houses were often females (even after 3 visits), city supervisors were requested to interview a randomly selected male when the selected male could not be reached after 3 house visits or to substitute a randomly chosen female for an unreached female; the complementary (second) lists were prepared preceding the field study accordingly. It is noteworthy that there was no requirement for a gender balance in selection of the master lists. For each incomplete interview, the reason for missing data was recorded together with the sex and age of the originally selected individual and this information was further used to compare and contrast the characteristics of missing and completed interviews.

\section{Data collection}

\section{Questionnaire}

Data were collected via face-to-face interviews in households from each randomly selected individual using a standard questionnaire. This questionnaire included a total of 43 questions on sociodemographic characteristics, knowledge about the health hazards of passive smoking, awareness about the new smoke-free legislation, level of support for the new legislation, exposure to any anti-smoking media messages related to the publicizing of the 
new regulations and frequency of use of smoke-free eating places after the legislation. Inquiries were based both on open-ended questions and on opinions provided for given statements and/ or conditions. For example, study participants rated their approval level (on a 5-level Likert scale) for statements, such as "The new legislation prohibiting smoking in workplaces will never work in Turkey-people will continue to smoke wherever they want" or "The new legislation prohibiting smoking in workplaces is a good idea because exposure to secondhand smoke is a direct threat to our health".

\section{Fieldwork}

To train provincial team leaders, provincial supervisors, regional supervisors and central supervisors a set of 3 consecutive "training of trainers" sessions of 2-3 days were held at 3 separate locations (to guarantee full attendance of the trainees). These trainings provided technical instructions on determination of lots, sample selection and other cityspecific preparations based on documents brought from 81 provinces and introduced the field manuals.

Prior to the field study, a pretest was conducted in the Ankara area on a convenience sample of rural and urban residents, aged 15 years or above. Supervisors travelled to the sites prior to initiation of the fieldwork, assisted with city-specific preparations, supervised the local interviewers, field controllers and provincial supervisors (from provincial health directorates) and also helped them with managing problems during data collection and/or transfer of the questionnaires to Ankara.

Field interviewers were chosen from among local nurses and midwives (as interviewers) and physicians (as controllers or provincial supervisors). Local interviewers, controllers and supervisors were trained on how to select a household and they could request assistance from the study centre (by phone) if required.

\section{Statistical analysis}

The major dependent variables in the study were knowledge about, support for and exposure to media messages about the new law. Other covariates included sociodemographic characteristics, smoking history, exposure to passive smoking, thoughts and behaviours on given statements (on tobacco-use in the public, exposure to media messages, etc.), (specific enquiries on) level of approval/support for prohibition of smoking in eateries in indoor places but not in open areas and experience with violation of the new law over the preceding 6 months (if any).

The data analyses included frequency and percentage distributions and calculation of prevalence rates with relevant standard errors (SE). Logistic regression modelling was used for multivariate analysis: modelling was conducted for 5 outcomes of interest: current smoking status; having knowledge on the new law; support for the new law; having knowledge on health hazards of passive smoking; and exposure to at least one anti-smoking media message. Models 5 and 6 additionally included current smoking status of the respondents, while model 3 was controlled for current smoking status and the knowledge on the new law in addition to the covariates in the first 3 models. Based on the sampling characteristics, all analyses were weighted, where weights were calculated as inverses of the sampling fractions. Statistical significance of the differences was discussed based on 95\% confidence intervals (CI) and SE, but chi-squared test $P$-values were also provided, with a pre-set alpha of 0.05 . All analyses were conducted using the statistical software package SPSS, version 15 , complex samples module.

\section{Results}

A total of 33187 questionnaires were returned from the field and optically scanned. Questionnaires with unacceptable and unreliable entries, missing more than $25 \%$ of the answers for 43 questions, with inconsistencies in control questions and missing information on sex and age were excluded in statistical analyses ( $n=215$ questionnaires). The results were therefore based on a total of 32972 questionnaires, completed by adults residing in all 81 cities throughout Turkey. The number of lots studied in each city ranged from 4 to 28 .

\section{Prevalence of smoking}

The prevalence of current smoking was found to be $33.8 \%$ (SE $0.07 \%$ ) in the Turkish adult population, corresponding to $46.9 \%$ (SE $0.01 \%$ ) of all adult males $(n=16064)$ and $20.9 \%(S D$ $0.08 \%)$ of all adult females $(n=16908)$. Of all quitters (4812 males and $2835 \mathrm{fe}$ males), 9.6\% (SE 1.0\%) of male quitters and $14.7 \%$ (SE 1.6\%) of female quitters reported that they stopped smoking within 6 months prior to the survey, meaning that they stopped smoking after the enactment of the new smokefree legislation.

\section{Awareness of and support for the new smoke-free law}

The rates of awareness about the new law, knowledge about health hazards of passive smoking and the level of support for the new law were studied by sex and current smoking status. Overall $57.7 \%$ of smokers and $47.7 \%$ of nonsmokers had heard/read a great deal about the smoke-free law and 34.3\% of smokers and $42.5 \%$ of non-smokers knew that passive smoking was a very serious risk to people's health (Table 1). More non-smokers (91.4\%) than smokers $(67.2 \%)$ were strongly in favour of the new law; an additional 5.3\% of non-smokers and $19.8 \%$ of smokers were somewhat in favour of the new law (Table 1).

Respondents were asked about their experience of seeing/reading/hearing messages about the new law in the media and/or in workplaces/indoor places where smoking was prohibited over the 


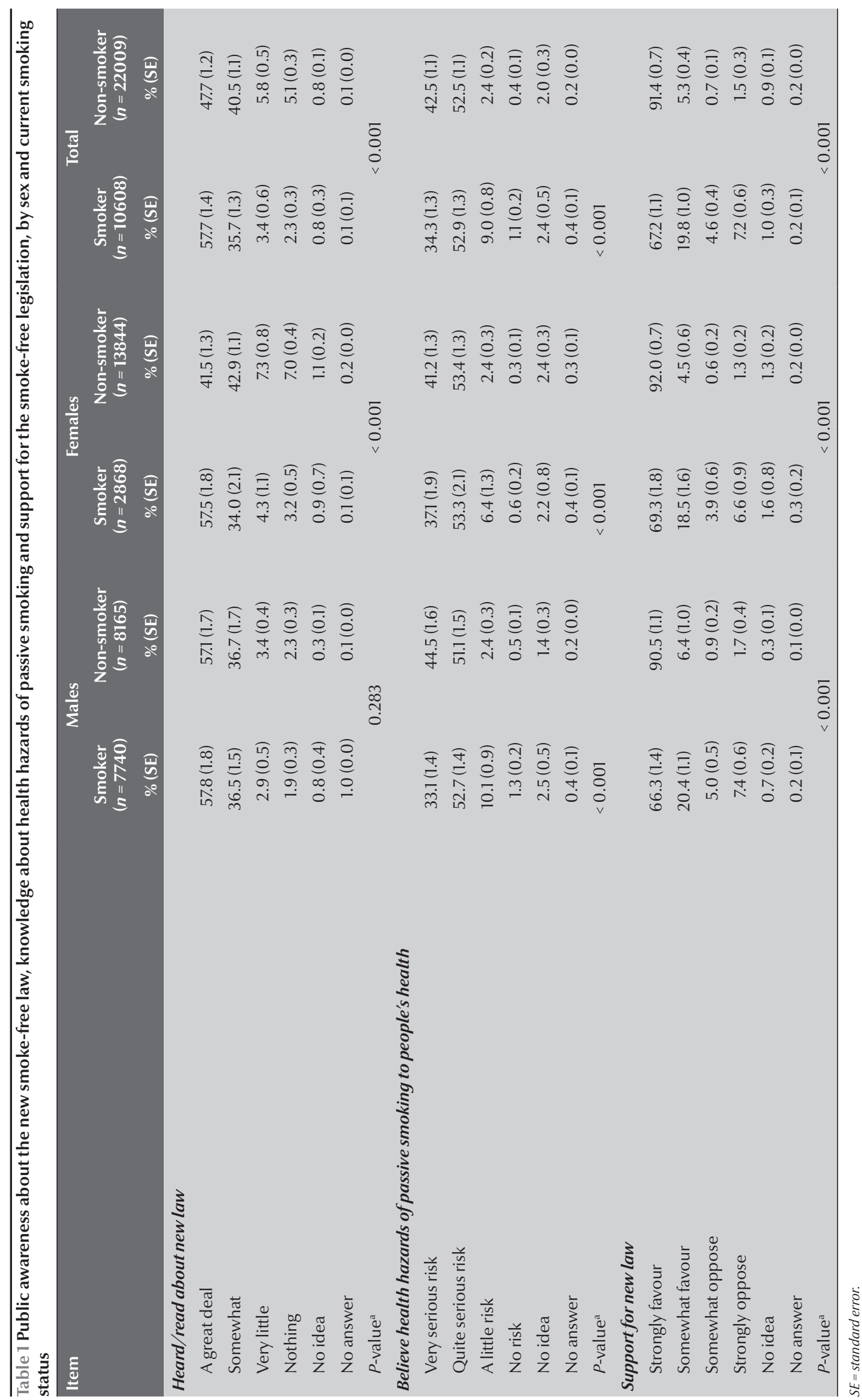


30 days preceding the survey (Table 2). While $96.1 \%$ of smokers and $88.9 \%$ of non-smokers had been exposed to such messages from at least 1 source, only $25.2 \%$ and $21.0 \%$ respectively had been exposed to such messages in all 4 of these sources.

Awareness about the new smokefree law (heard/read about the new law a great deal or somewhat versus other categories) was found to be associated with support for the new law (strongly/somewhat in favour versus other categories). In males, rates for support for the law were 92.8\% (SE $0.5 \%$ ) and $81.1 \%$ (SE 2.5\%) for those who were and were not aware about the law, respectively and in females the corresponding rates were $95.9 \%$ (SE $0.4 \%$ ) and $87.7 \%(\mathrm{SE} 1.5 \%)(\mathrm{OR}=3.29)$ respectively. The association between awareness of the law and support for the law was even stronger among current non-smokers. Examining awareness and support as binary variables as described above, among current smokers the rate of awareness about the new law and support for it were $87.7 \%$ (SE 0.8 ) and $71.1 \%$ (SE 0.4) respectively for males $(\mathrm{OR}=2.90)$ and $88.9 \%$ (SE $1.1)$ and $75.1 \%$ (SE 7.6) respectively for females $(\mathrm{OR}=2.67)$. Among current non-smokers the rates of awareness about and support for the new law were 97.9\% (SE 0.3) and 89.4\% (SE 1.4) respectively $(\mathrm{OR}=4.49)$ for males and 97.9\% (SE 0.5) and 89.3\% (SE 2.1) respectively for females $(\mathrm{OR}=5.44)$.

\section{Respondents' experiences after the ban}

Two Likert-type questions were used to enquire about respondents' experiences of visiting restaurants, bars and teahouses in shopping malls after the smoking ban. About 4 out of 5 smokers $(78.7 \%)$ reported that they found such places more enjoyable or found no difference than before the law ( $\mathrm{Ta}$ ble 3). Smokers reported so in $70.9 \%$ of the cases. About one-fifth (20.4\%) of non-smokers and $9.5 \%$ of smokers reported that they visited restaurants, bars and cafes inside shopping malls more often after the new law. Altogether, the study findings revealed that the claims about a significant decrease in use of shopping malls and/or restaurants inside such malls due to the smoking ban regulations were not well-grounded.

\section{Risk factors}

Sociodemographic characteristics and potential risk factors gathered from the present data were simultaneously studied to model status of awareness about the new law (present versus absent), knowledge of health hazards of passive smoking (present versus absent) and support for the new law (support versus no support), using logistic regression modelling. In all models, the same 5 sociodemographic characteristics (age, educational attainment, marital status, number of children and presence of any paid job outside the home) were included in models because these variables were either primary risk factors for smoking and/or might affect individuals' smoking habits/smoking-related perceptions directly. Sex, as done in other analysis, was considered as an effect modifier, and multivariate models were done separately for males and females (Tables 4 and 5). The principal finding was that current smoking and awareness of and support for the new law were all significantly associated with individuals' knowledge about the health hazards of passive smoking. Those who had knowledge about passive smoking were more likely to be aware of the new law $(\mathrm{OR}=2.89$ and $\mathrm{OR}=2.60$ for males and females respectively) and to support the law $(O R=5.02$ and 5.39 for males and females respectively), while current smokers were less likely to know about the risks of passive smoking (OR $=3.73$ and 1.94 for males and females respectively).

\section{Discussion}

\section{Use of the LQT in this survey}

The study did not include a specific methodological component to investigate the robustness of prevalence estimates obtained from this study. However, the Global Adult Tobacco Survey (GATS), an international study [7], was being conducted in Turkey at the same time as our field study, with special emphasis on tobacco use

\begin{tabular}{|c|c|c|c|c|c|c|}
\hline \multirow[t]{3}{*}{ Exposed to messages about new law } & \multicolumn{2}{|c|}{ Males } & \multicolumn{2}{|c|}{ Females } & \multicolumn{2}{|c|}{ Total } \\
\hline & $\begin{array}{c}\text { Smoker } \\
(n=7740)\end{array}$ & $\begin{array}{l}\text { Non-smoker } \\
\quad(n=8165)\end{array}$ & $\begin{array}{c}\text { Smoker } \\
(n=2868)\end{array}$ & $\begin{array}{c}\text { Non-smoker } \\
(n=13844)\end{array}$ & $\begin{array}{c}\text { Smoker } \\
(n=10608)\end{array}$ & $\begin{array}{l}\text { Non-smoker } \\
(n=22009)\end{array}$ \\
\hline & $\%$ (SE) & $\%$ (SE) & $\%$ (SE) & $\%$ (SE) & $\%$ (SE) & $\%$ (SE) \\
\hline From at least 1 source & $96.2(0.4)$ & $94.1(0.6)$ & $95.8(0.5)$ & $85.4(0.7)$ & $96.1(0.3)$ & $88.9(0.5)$ \\
\hline$P$-value ${ }^{\text {a }}$ & \multicolumn{2}{|c|}{$<0.005$} & \multicolumn{2}{|c|}{$<0.001$} & \multicolumn{2}{|c|}{$<0.001$} \\
\hline From all 4 of these sources & $24.7(1.3)$ & $23.3(1.0)$ & $25.6(1.9)$ & $17.3(1.0)$ & $25.2(1.1)$ & $21.0(0.8)$ \\
\hline$P$-value ${ }^{\mathrm{a}}$ & \multicolumn{2}{|c|}{0.348} & \multicolumn{2}{|c|}{$<0.001$} & \multicolumn{2}{|c|}{$<0.001$} \\
\hline
\end{tabular}

${ }^{a}$ Chi squared test.

$S E=$ standard error 


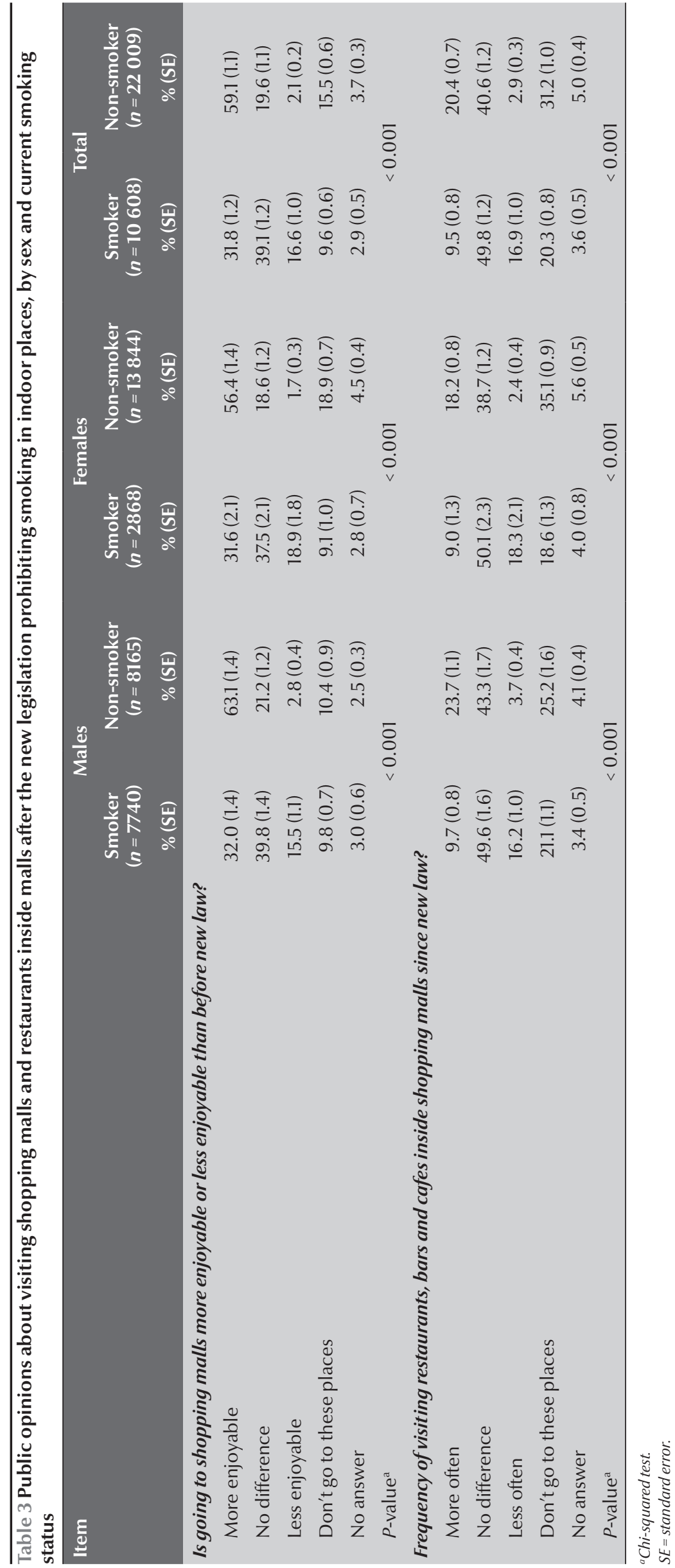

among Turkish adults. Both studies used the same set of questions for sociodemographic characteristics and smoking history. GATS used a multistaged stratified systematic cluster sampling technique and the estimated prevalence of tobacco use. In GATS, on a total of 9030 adults, the prevalence of current smoking was found to be $31.1 \%$ (95\% CI: $29.9 \%-32.4 \%$ ) and the corresponding prevalence in our survey was $33.8 \%$ (SE 0.07\%) for the same age group. The closeness of the 2 prevalence rates suggests that the LQT method can be considered as a robust method, besides its simplicity and ease of use.

The relatively ease of the method, together with no absolute need for complete sampling frames, makes LQT-based sampling very suitable for conducting tobacco-related surveys nationwide. The LQT enabled us to identify subpopulations in which awareness of and support for the new law were above or below the threshold of expected levels and hopefully this will allow local personnel to focus their future anti-tobacco efforts and resources in the most cost-efficient way. The survey was also important in terms of national capacity development for tobacco-related surveillance activities. Both the core team of the tobacco control unit in the General Directorate of Primary Care at the $\mathrm{MoH}$ and heads of tobacco control units in provincial health directorates had the opportunity to take an active part in planning and implementation of a large survey at the national level.

\section{Prevalence of smoking}

The baseline data of this study confirmed that, despite all efforts, current smoking is still common in Turkey (46.9\% of adult males and $20.9 \%$ of adult females). Quitting rates over the 6 months following the first phase of the new smoke-free law (9.6\% of males and $14.7 \%$ of females) were about twice the comparable rates before $[1,8]$. This 


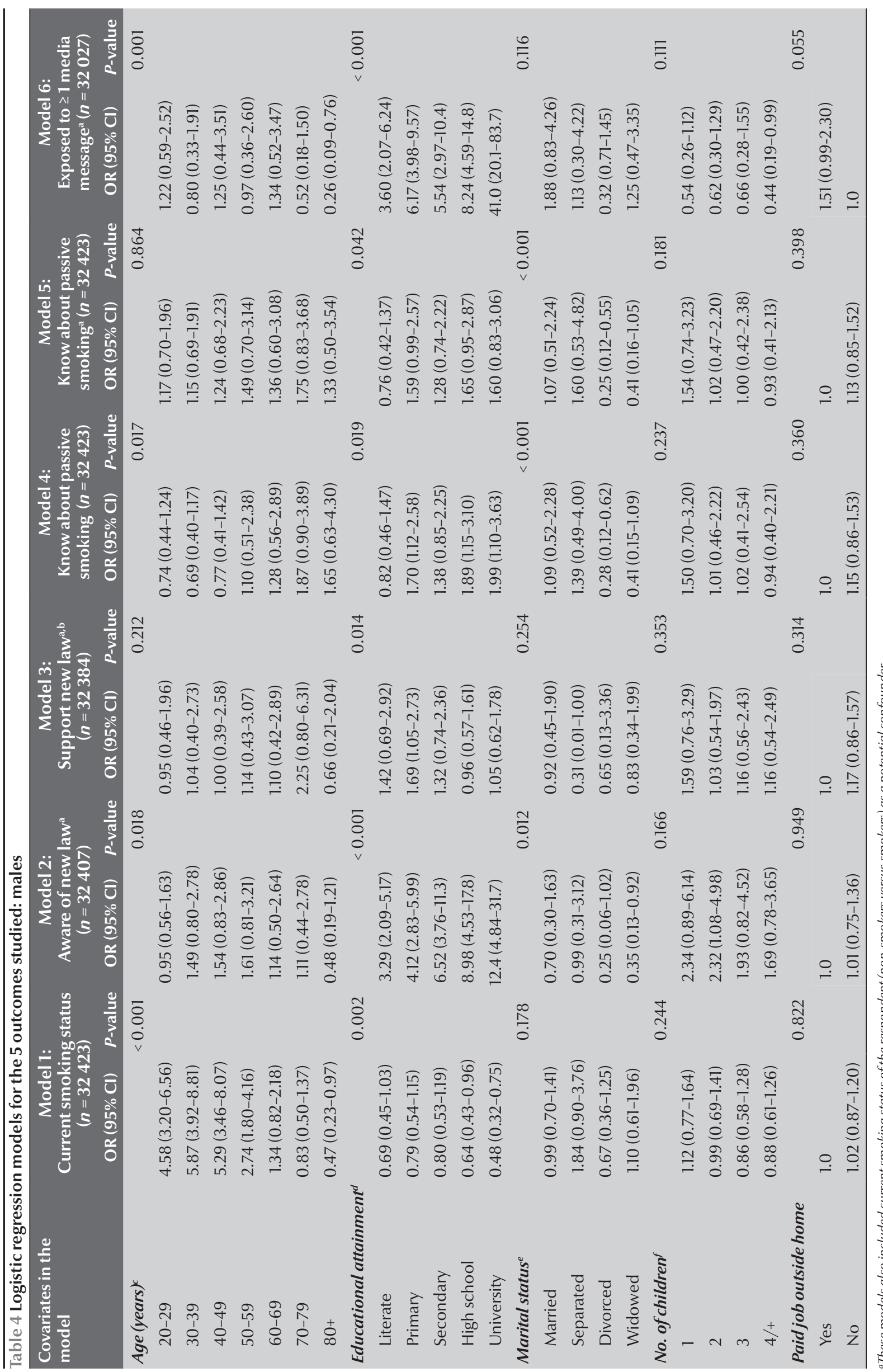




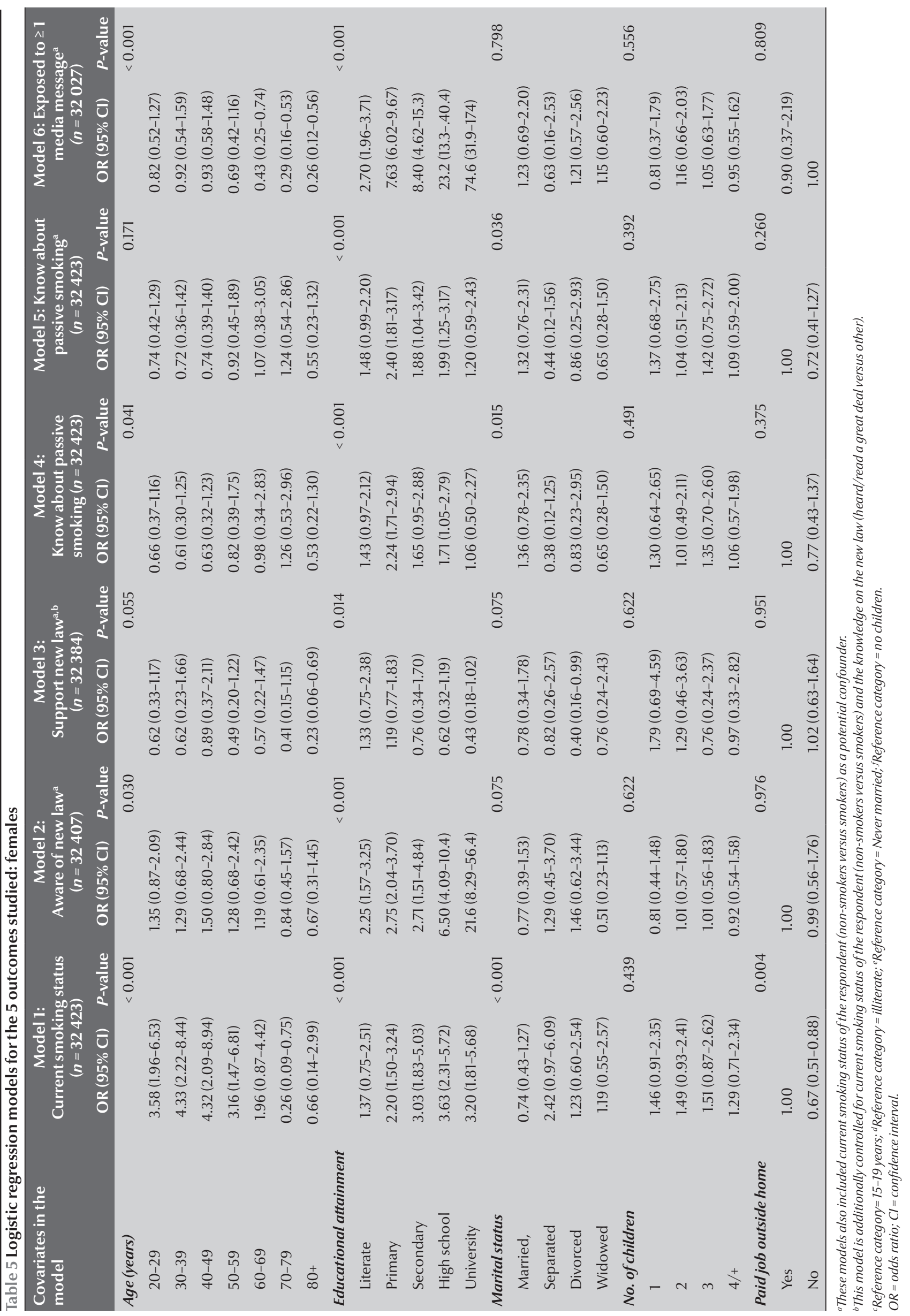


phase of the programme included efforts to increase the public awareness about the health hazards of smoking and its economic burden and an increase in the number of smoking cessation clinics. Further studies are needed to investigate whether smoking bans, especially those in the workplace, affect quit rates directly.

\section{Awareness of and attitudes to the new national tobacco control laws}

The main findings of this survey revealed that the rate of awareness about the new smoke-free law was fairly high among the general public ( $47.7 \%$ of non-smokers and $57.7 \%$ of smokers knew about the law) and the law was supported by a high proportion of Turkish adults, even among current smokers $(91.4 \%$ of non-smokers and $67.2 \%$ of smokers strongly favoured the new law). Furthermore, it is noteworthy that, controlling for smoking status, one of the strongest, yet modifiable, risk factors among the studied predictors of awareness and attitudes was the general public's knowledge about the health hazards of passive smoking. Those who knew about the dangers of passive smoking were nearly 3 times more likely to know about the law and were over 5 times more likely to support the new law. Current smokers were significantly less likely to have knowledge about the health effects of passive smoking than were smokers. This highlights the importance of increasing the awareness of the general public about the health threats of passive smoking in future interventional activities. Identification of subpopulations with less knowledge and/or support for the law will lead to effective targeted plans for intervention.

The new 100\% smoke-free law banned smoking in closed areas in Turkey such as shopping malls. It is important to note that $31.2 \%$ of nonsmokers reported that they did not go to eating places in shopping malls and about $20.3 \%$ of smokers did not go to shopping malls at all. Thus studies conducted to those visiting shopping malls, as is usually the case when monitoring tobacco control activities, cannot capture about $20 \%-30 \%$ of the general adult population and inferences based on data from this method will therefore be biased.

Regardless of sex, there was a positive and dose-response association between educational attainment and awareness about the new law and about the risks of passive smoking to smoking-related media messages, matching our expectation that better educated people may have more access to the media than their counterparts with lower educational attainment. The content and transmission of anti-smoking media messages may need to be improved for better use by the population with low educational attainment.

Last but not least, the study revealed, at a national level, that individuals did not change their frequency of visits either to shopping malls or to the eateries inside such malls after the ban. Even more importantly, 59.1\% of non-smokers and $31.8 \%$ of smokers agreed that they found smoke-free shopping malls "more enjoyable than before" and $20.4 \%$ of non-smokers and about $9.5 \%$ of smokers even reported increasing their visits to smoke-free restaurants in shopping malls after May 2008. The results can be seen as important in putting an end to the discussion of unfair business in the hospitality sector after the smoking ban in May 2008, in favour of the eateries outside the indoor areas.

\section{Limitations of the study}

It is important to note that the findings about the awareness of the new smokefree law were based on self-reports; evaluation of the actual content of this knowledge was beyond the scope of this study. In evaluating the level of support for the new law all participants were first informed about the new law, with a standard sentence explaining it. Later, each individual was asked whether s/ he was in favour of the law or opposed it. Therefore, no "differential" misclassification bias (if any) was expected due to a difference (if any) in knowledge on the new law and/or current smoking status. Besides a general statement about the support for the new 100\% smoke-free law, several statements regarding smoking bans were presented to the interviewed individuals and their opinions were obtained.

\section{Conclusion}

This study has provided important findings about the awareness of the general public in Turkey about the new 100\% smoke-free law and the level of compliance with the law. Even more important for the international literature, we demonstrate the use of the LQT in a tobacco-related survey in a developing country. We believe that conducting similar surveys would be of great benefit in developing countries not only for tobacco control surveillance, but to develop national capacity to provide evidence on a variety of other health topics of interest at the local level.

\section{Acknowledgements}

This survey was supported technically and/or financially by the World Health Organization- Tobacco Free Initiative, World Health Organization Regional Office for Europe, World Health Organization Country Office (Turkey) and the US Centers for Disease Control and Prevention; and the Turkish Ministry of Health, Primary Health Care General Directorate, Tobacco Control Unit, within the scope of Bloomberg Initiative to Reduce Tobacco Use.

The authors would like to thank Cevdet Erdol, Jo Bickmayer, Nichole 
Veatch, Stephen Hamill, Wick C. Ayfer Aytemur. Hayati Baykan, HüWarren, Juliette Lee, Veronica Lee, seyin İlter, Serdar Acar, Derya Özkaya, Meltem Sengelen, Meliksah Ertem, Pinar Pazarli, Osman Elbek and Zeynep
Irmak Arpad, Gokturk Demirel, Toker

Erguder; and all physicians, nurses, midwives, health technicians and drivers who took part and all other colleagues at the provincial health departments.

\section{References}

1. Sferrazza L et al. Using polling for smoke-free implementation and enforcement in Turkey. Paper presented that the 14th World Conference on Tobacco or Health, Mumbai, 8-12 March 2009.

2. Robertson S. Monitoring immunization services using the lot quality technique. Geneva, World Health Organization, 1996 (WHO/VRD/TRAM/96.01).

3. Lemeshow $S$, Taber $S$. Lot quality assurance sampling: singleand double-sampling plans. World Health Statistics Quarterly, 1991, 44:115-132.

4. Robertson SE, Valadez JJ. Global review of health care surveys using lot quality assurance sampling (LQAS), 1984-2004. Social Science and Medicine, 2006, 63:1648-1660.
5. Buzgan T et al., eds. Initial 6-month evaluation of the effects of the 100 percent-smoke-free legislation and health hazards of passive smoking: and evaluation of the coverage of the related mass media campaign. Ankara, Turkey, Ministry of Health, xxxx .

6. Sample LQ software package. Brixton Health [website] (http:// www.brixtonhealth.com/index.html, accessed 22 July 2012).

7. Global Adult Tobacco Survey.Turkey report-2010. Ankara, General Directorate of Primary Health Care, Ministry of Health, 2010 (MoH Publication No. 803).

8. Bilir $\mathrm{N}$ et al. Tobacco Control in Turkey Copenhagen, Denmark, World Health Organization Regional Office for Europe, 2009. 